\title{
EPIDEMIA DE ENCEFALITE POR ARBOVIRUS
}

\author{
A Enfermeira e o Hospital de Emergência - segundio \\ experiência durante epidemia no Litoral Sul \\ de São Paulo - 1975
}

* Maria Tereza Müller

** Dorothee Völckers

RBEn/06

MULLER, M.T., VOLCKERS, D. - Epidemia de encefalite por arbovirus. Rev. Bras. Enf.; DF, $30: 115-120,1977$.

\section{INTRODUÇÃO:}

No começo de 1975 ocorreu uma epidemia de Encefalite por Arbovirus, no Litoral Sul de São Paulo, nos municípios de Peruíbe, Itanhaém e Mongaguá.

Entre nós, até então, a Encefalite não tinha sido observada sob forma epidêmica. Os doentes estavam sendo encaminhados para Santos, a 40-70 quilômetros de distância por falta de hospital na região.

A população deste é composta de amostras socialmente diversas:

a) de hábitos urbanos: comerciantes, hoteleiros, servidores públicos, imobiliários;

b) flutuantes: os denominados turistas, procedentes em geral, do planalto;

c) a terceira parcela é integrada de trabalhadores urbanos e rurais.
Os trabalhadores urbanos dedicam-se habitualmente ao serviço de limpeza de ruas e terrenos, aberturas de vias públicas, zeladoria, de imóveis, enquanto que os trabalhadores rurals dedicam-se, em sua maioria, ao plantio e colheita de bananas. Este último grupo, constituia-se de individuos cujas tarefas os expunham aos mosquitos silvestres. Foram eles os mais duramente atingidos pela doença.

A situação se agravou até ponto critico, em virtude da inexistência de hospital na região e da alta letalidade produzida pela doença. Foi quando se julgou necessário a instalação, em caráter urgente, de um Hospital de Emergência.

Aos 13/04/75, após divisão em grupos para o estudo da montagem de um Hospital de Emergência realizou-se reunião com o Senhor Secretário da Saúde de

* Enfermeiras do Hospital Emílio Ribas - São Paulo. 
MULLER, M.T., VOLCKERS, D. - Epidemia de encefalite por arbovirus. Rev. Bras. Enf.; DF, 30 : 115-120, 1977.

São Paulo que, após ter ouvido todos, calculou para a instalação do Hospital Emergência 72 horas; foi conseguido, na realidade, em 56 horas. Iniciou-se então o plano de montagem para um Hospital de Emergência na Colônia de Férias da Polícia Militar de São Paulo, em Itanhaem.

Foi calculada estimativa de verba necessária para compra de equipamento, permanente e consumo. No hospital Emilio Ribas - Instituição Base - o Serviço de Enfermagem verificou de que material excedente dispunha da epidemia de Meningite de 1974. Havia quase todo equipamento e o que faltou foi completado com o material em uso no próprio Hospital: - carrinho de medicação, macas, cadeiras de roda, 1 divã, suportes de soro, 1 quadro negro e 2 máquinas de escrever. As camas, berços, suportes de roupa de madeira foram retirados do depósito do Hospital. Não havia nenhuma disponibilidade de material permanente. $O$ que enviamos foi do nosso material em uso como: bacias, cubas, aparelhos de P. A., baldes, jarros, caixa de traqueostomia caixa para veno-secção, caixa para pequena cirurgia, aspiradores de secreção, torpedos de $\mathrm{O}_{2}$ estetoscópios, martelo de reflexo, Bird, manômetros de torpedo, autoclave semi-rápida.

Material de consumo tínhamos alguma disponibilidade e enviamos tudo para o início do Hospital de Emergência para 50 leitos.

As firmas fornecedoras de material permanente, equipamento e consumo atenderam prontamente os nossos pedidos. Conseguimos em três dias todo o material inclusive uma autoclave.

\section{PESSOAL}

Equipe multi-profissional foi recrutada do Hospital "Emilio Ribas" - Instituição Base e, mais, dos Hospitais do Mandaqui (S.P.), do Cândido Fontoura (S.P.) e de Pariquera-Açu (Vale do Ribeira). Integraram-se: 2 médicos gra- duados em Administração Hospitalar e com especialização em Doenças Transmissíveis. Cerca de uma dezena de jovens médicos compuseram o Corpo Clínico. O grupo da Enfermagem foi chefiado por profissional com pós-graduação em Administração Hospitalar e também com larga experiência em Doenças Transmissiveis. Uma nutricionista, uma assistente social, educadores sanitários, engenheiros-sanitaristas, biologistas e técnicos de laboratório, integrantes da equipe, centralizaram na sede do Hospital de Emergência, suas atividades.

O pessoal escolhido para atuar em Hospital de Emergência deve ser experiente e responsável. Os funcionários do Hospital "Emilio Ribas" que voluntariamente se ofereceram para atuar naquele Hospital, foram selecionados.

Previsão para 50 doentes:

Enfermeiras .............. 3

Auxiliares de Enfermagem .... 5

Escriturário de Enfermagem .. 1

Atendentes .............. 3

Foram ainda: médicos, nutricionistas, cozinheira, serventes de cozinha, lavanderia, rouparia e telefonista.

No primeiro dia foram 17 serventes para limpeza da colônia, que esteve muito tempo fechada. Esse pessoal voltou no final do dia, permanecendo apenas 5 no local.

De outros hospitais da Secretaria da Saúde foram enviados atendentes e auxiliares de enfermagem, a saber:

Hospital Cândido Fontoura:

1 auxiliar de enfermagem

1 atendente

Parque Hospitalar do Mandaqui:

1 auxiliar de enfermagem

7 atendentes

De Vale:

2 atendentes 
MULLER, M.T., VOLCKERS, D. - Epidemia de encefalite por arbovirus. Rev. Bras. Ent.; DF, $30: 115-120,1977$.

Esse quadro não permaneceu o mesmo até o fim. Após a primeira quinzena retornaram 2 enfermeiras, 2 auxiliares de Enfermagem e 2 atendentes; com 0 declínio da epidemia alguns funcionários retornaram aos seus Hospitais.

A colaboração das Escolas de Enfermagem e Escolas de Auxiliares de Enfermagem se fez presente até o final do evento:

Escolas de Auxiliares de Enfermagem:

\begin{abstract}
de Pariquera-Açu
de Assis

São Joaquim

Fac. de Enf. do Instituto

Adventista de Ensino

Alunas do Curso de Pósgraduação de Enfermagem da Universidade de São Paulo
\end{abstract}

2 alunas

TOTAL:

57 alunos

\section{LOCAL ESCOLHIDO E CASUISTICA}

O local eleito para a instalação do Hospital foi o de uma colônia de férias, pertencente a Polícia Militar do Estado, em Itanhaem, à meia distância entre os municípios de Peruíbe e Mongaguá. $O$ edifício se situa entre a estrada que dá acesso a Itanhaém e o mar. A edificação, térrea, é formada por um conjunto de 6 alas, com 79 quartos, dispondo de cozinha ampla, refeitório e lavanderia que estava bem equipada com 2 máquinas lavadoras, 1 secadora e 1 calandra. Uma máquina lavadora não estava funcionando por falta de peça; com a colaboração de Firma especializada em São Paulo, esta funcionou em pouco tempo.

A rouparia da colônia de férias atendeu as primeiras necessidades do Hospital e dos funcionários; a comunidade local forneceu em 24 horas pedido de roupas de cama, pijamas, cobertores; le- vou ainda brinquedos, chinelos, congas, e telas para as janelas.

Concentraram-se os doentes em 2 alas onde se dispuseram 48 leitos em 24 pequenos quartos. Para crianças foram dispostos 20 berços em 4 salas mais espaçosas. Cada quarto dispunha de vaso sanitário, lavatório e chuveiro.

Em ponto central da Enfermaria foi instalada a sala de serviço e o posto de enfermagem. A sala de admissão foi montada em ala central, junto ao Setor de Informaçōes e de Arquivo Médico.

Foi adaptada para enfermaria de cuidados intensivos uma área anteriormente destinada a jogos.

Numerosas outras adaptaçōes foram requeridas para funcionamento dos vários setores:

1. instalação elétrica para 110 e 220 volts nos quartos, pois o equipamento utilizado em São Paulo é de 110 volts, enquanto predominava, na área litorânea, a voltagem de 220 ;

2. telagem de janelas, visando diminuir o rísco de exposição do pessoal a mosquitos transmissores;

3. instalação de pias, com tampos de mármore de 1,80 metros, na sala de serviço, na enfermaria de cuidados intensivos e na de pediatria e de lavabo na sala de admissão;

4. iluminação fluorescente, na enfermaria de cuidados intensivos;

5. construção de rampas de acesso em substituição dos degraus de corredores;

6. construção de passarelas de cimento sobre a areia da praia, para transporte de carros térmicos, de refeição;

7. instalação de autoclaves elétricas, sendo uma semi rápida e outra comum.

Para assistência mais adequada aos individuos que se tornaram portadores de seqüelas - os quais foram estimados em cerca de $1 / 3$ - instalou-se uma enfermaria com equipamentos fisioterápicos rudimentares, de construçāo local e quase todo o tempo sem fisioterapeuta ou médico fisiatra. 
MULLER, M.T., VOLCKERS, D. - Epidemia de encefalite por arbovirus. Rev. Bras. Enf.; DF, $30: 115-120,1977$.

O Hospital atuou de $16 / 4$ até $30 / 6 / 75$, quando foi desativado.

O Serviço de Arquivo Médico e Estatística (SAME), implantado tāo logo o Hospital de Emergência teve seus trabalhos iniciados, registrou o seguinte movimento: foram internados 242 doentes, em sua maioria adultos. Cerca de $2 / 3$ da casuística foi composta por indivíduos do sexo masculino e $1 / 3$ do sexo feminino; destes, 51 eram crianças.

Ocorreram 6 óbitos e 12 transferências para outros Hospitais de maiores recursos.

\section{CUIDADOS DE ENFERMAGEM NA ENCEFALITE \\ EPIDEMIA NO HOSPITAL DE EMERGENCIA DE ITANHAEM}

A encefalite observada no Hospital de Emergência, foi doença de caracteristicas muito graves, por afetar órgāo nobre, como o Sistema Nervoso Central (S.N.C.), por causar letalidade elevada e por determinar seqüelas.

A Encefalite em causa foi atribuida a ưm arbovirus. As arboviroses sāo infecções originárias de animais (antropozoonoses). No Brasil, nāo se conhece ainda os animais amplificadores da doença.

O ciclo infeccioso das arboviroses, é, em geral, mais complexo que o de outras doenças transmissiveis, por incluir numerosos fatores:

a) o arbovirus (agente da infecçāo);

b) os hospedeiros vertebrados susceptíveis (reservatórios);

c) os artrópodes (vectores) e

d) o homem, habitualmente constando como elemento final da cadeia de transmissāo.

A designação de "arbovirus" deriva da uniāo das primeiras sílabas do inglês "Arthropod Borne Viruses", e que encerra o significado de "virus disseminados por artrópodes".
Determinam doenças, tais como, Febre Amarela, Dengue e, entre outras, a Encefalite.

$O$ homem se infecta pela picada dos mosquitos transmissores. Nem todos os individuos infectados apresentam as caracteristicas de manifestações do comprometimento do encéfalo.

Os doentes foram admitidos no Hospital com as principais queixas de: hipertermia, cefaléia intensa, tonturas, dificuldade de linguagem falada e fraqueza dos membros.

Durante o período de hospitalizaçāo pode-se observar outras características: alterações de consciência, letargia, tremores, disartria, paralisias.

No início da doença foi muito importante observar o repouso do doente e vigiá-lo rigorosamente para a prevençāo das quedas, as quais ocorriam como resultado das tonturas, da fraqueza muscular e do desequilíbrio; chegou-se a tal conclusāo após observar que os doentes que sofreram queda pioravam na evolução clínica. Após tal observação, foi redobrada a vigilância de enfermagem, e procurou-se conscientizar o doente acerca de seu estado.

A imobilizaçāo, por faixas de contenção foi necessária para doentes com alteração de consciência. Nesses e naqueles que apresentaram paralisias, a mudança de decúbito era feita de 2 em 2 horas. Nāo foram observadas escaras de decúbito.

Os dados vitais eram controlados, com rigor, para observar as alterações mais correntes numa doença até entāo nāo observada entre nós.

Verificou-se que os picos febris apareciam até o $3 .^{\circ}, 4 .^{\circ}$ dia de internaçāo, e mais no periodo da tarde; queda em lise.

Observou-se que alguns doentes apresentaram dificuldade respiratória. $O$ estado destes geralmente se agravava com a presença de secreçāo brônquica, de 
MULLER, M.T., VOLCKERS, D. - Epidemia de encefalite por arbovirus. Rev. Bras. Enf.; DF, $30: 115-120,1977$.

início espessa, de cor amarelada; tornava-se mais fluida e muito abundante após a instalação de nebulizadores e fluidificadores de secreção, sendo necessária aspiração e observação constante. Alguns foram removidos para Hospital de retaguarda para traqueostomia e instalação de respiração artificial.

$\mathrm{Na}$ alimentação do doente observou-se que a não aceitação era motivada por causas variadas; cefaléia intensa geralmente acompanhada de náuseas e tonturas, hábitos alimentares redundantes de situação sócio-econômica e ou individual e mal estar geral.

As náuseas e vômitos ocorriam mais no horário das refeições ou da medicação oral.

Alguns doentes apresentaram retenção urinária, sendo necessário o cateterismo vesical, após prescrição médica.

A doença não era sensivel a medicamentos; a medicação era apenas sintomática.

\section{CONSIDERAÇOES FINAIS}

- Estabelecido o local do Hospital de Emergência, a enfermeira deverá tomar ciência da planta física, providenciar limpeza e rociamento da área antes da instalação.

- E necessário ter hospital na retaguarda, com recursos técnicos mais sofisticados.

- A equipe de enfermagem na Encefalite Epidêmica, deve ser bem orientada quanto a observação e vigilância dos pacientes, nas 24 horas; essa vigilância era recomendada principalmente para os doentes que apresentaram tontura, fraqueza muscular, incoordenação motora e que poderiam ao levantar-se, sofrer queda.

- Na convalescença, os doentes que apresentaram seqüela, eram acompanhados por atendentes na deambulação; quando as condições permitiam, eram conduzidos até a praia onde faziam exercícios de marcha na areia e tomavam banhos de mar. Cada doente nessas condições necessitava do auxílio de 1 ou 2 atendentes.

- Eram levados ainda à sala de físioterapia, instalada com aparelhos feitos na própria colônia e os exercícios eram feitos com orientação médica e de enfermagem.

- Foi sentida necessidade de um especialista em Medicina Física e um Fisioterapeuta.

- Devem fazer parte da equipe hospitalar do Hospital de Emergência: eletricistas, encanadores e carpinteiros.

- Constatou-se que, com atendimento precoce, hospitalar, o número de óbitos, que se situava em torno de $30 \%$ baixou para $4 \%$.

\section{QUANTO A PESSOAL}

- Alunos de Escolas de Enfermagem devem ser acompanhados de instrutor;

- ser aluno do $2 .^{\circ}$ ano de Auxiliar de Enfermagem ou do $3^{\circ}$ ano de Enfermagem;

- cada grupo deve permanecer um mínimo de 14 dias no hospital de emergência;

- o revesamento dos grupos deve ser perfeito para não haver sobreposição de escolas e nem lacunas entre um grupo e outro;

- a coordenação das Escolas deve ser de comando único e de poder decisório;

- os entendimentos quanto a ida ou vinda de alunos, deve ser previamente conhecida da enfermeira responsável do hospital de emergência, a fim de prever alojamento;

- uma vez estipulada a quantidade de alunos necessários para o Hospital de Emergência, deve-se prover sempre o mesmo número;

- a responsabilidade do comportamento do aluno deve caber a ele próprio; daí a importância da seleção dos mesmos;

- uma vez instalado o "Hospital de Emergência" as chefias das diversas equi- 
MULLER, M.T., VOLCKERS, D. - Epidemia de encefalite por arbovirus. Rev. Bras. Enf.; DF, $30: 115-120,1977$.

pes deverão permanecer até o fechamento do mesmo. importante lembrar que - pessoal que aí prestou serviços são de procedências de diversos hospitais e a liderança deve se fazer presente para que não haja quebra na harmonia do grupo de trabalho.

- concluiu-se que os objetivos propostos: o cuidado do doente, a pesquisa, foram alcançados satisfatoriamente com 0 trabalho conjunto de uma grande equipe acionada com rapidez e muito bem conduzida pela Secretaria da Saúde do Estado de São Paulo.

São Paulo, 28 de malo de 1976

Este trabalho fol elaborado pelas Enfermeiras do Hospital "Emilio Ribas";

Maria Tereza Müller Dorothee Völckers

\section{RESUMO}

- Instalação de um Hospital de Emergência, em setenta e duas horas, para encefalite epidêmica, por Arbovirus em Itanhaém, 1975.

- As providências tomadas quanto ao material e pessoal para esta instalação.

- Utilização e adaptação de uma colônia de férias para tal fim.

- Equipe multi-profisisonal reunida num esforço conjunto para dar melhor assistência hospitalar aos doentes, dentro das limitaçōes impostas pelas circunstâncias.

- A atuação da Enfermagem nessa Equipe fol de suma importância, contribuindo através da observação permanente e de suas anotaçōes, para a elucidação do diagnóstico. 